ISSN 1991- 8690

website: http://jsci.utq.edu.iq

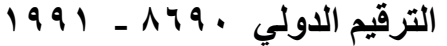

Email: utjsci@utq.edu.iq

\title{
Isolation of the vancomycin resistant enterococci from different sources
}

\author{
Khwam R. Al-Husseiny Thaar Ali Hussain Yahya A. Abass \\ Medical Dep- Al-Nassyria Technical Institute
}

\begin{abstract}
A total of sixty five isolates of enterococci were isolated; thirty six isolates from clinical samples (stool, urine, vaginal swabs, intra-abdominal and pelvic wounds and blood cultures) and twenty nine isolates from hospital environment (operating theaters, bed wards, floor, medical instruments, and sewage).

The results revealed that 14 isolates ( $(1.53 \%$ ) were vancomycin-resistant enterococci including 8 isolates from clinical samples and 6 isolates from hospital environment. Moreover, 8 isolates (12.30\%) showed intermediate resistance, and remaining (43) isolates are sensitive to vancomycin
\end{abstract}

\section{Introduction:}

Enterococci are part of the normal intestinal flora of humans and animals but are also important pathogens responsible for serious infections. The genus Enterococcus includes more than 17 species, but only a few, Enterococcus faecalis and Enterococcus faecium, account for most clinical infections in humans[1]. With increasing antibiotic resistance, enterococci are recognized as feared nosocomial pathogens that can be challenging to treat [2].

Enterococcus species are hardy, facultative anaerobic organisms that can survive and grow in many environments. In the laboratory, enterococci are distinguished by their morphologic appearance on Gram stain and culture (gram-positive cocci that grow in chains) and their ability to : hydrolyze esculin in the presence of bile, grow in 6.5\% sodium chloride, demonstrate pyrrolidonyl arylamidase and leucine aminopeptidase, and react with group D antiserum. They were formerly known as group D streptococci until assigned their own genus [3]. 
Vancomycin-resistant enterococci (VRE), first reported in Europe in 1988, are emerging as a global threat to public health, the incidence of VRE infection and colonization among hospitalized patients has increased rapidly in the last years [4]. From 1989, the year VRE was first identified in the United States, through 1993, the proportion of enterococcal isolates resistant to vancomycin reported to the National Nosocomial Infections Surveillance System (NNISS) increased 20-fold [ 5 ]. Infection with VRE may be associated with increased mortality, and no effective antimicrobial therapy is available for many VRE [6]. Enterococci are important nosocomial pathogens [7]. Their emergence in the past two decades is in many respects attributable to their resistance to many commonly used antimicrobial agents [ 8].

The aim of this study is to detect the prevalence of vancomycin resistant enterococci in clinical causes and in environment of hospital.

\section{Materials and Methods:}

The study was carried out from January to June 2008 at A-Nassyria general hospital .A total of sixty five of enterococci (36 isolates from clinical samples and 29 isolates from hospital environment) were isolated. The clinical isolates were collected from stool, urine, vaginal swabs, intra-abdominal and pelvic wounds and blood cultures. The environmental samples were collected from operating theaters, bed wards, floor, medical instruments, and sewage (table 1). Presumptive enterococci were identified on the basis of Gram stain, catalase reaction, grow in presence of bile and hydrolyze esculin (bile esculin-positive) and they grow in $6.5 \% \mathrm{NaCl}$ [9]. Minimum inhibitory concentrations (MIC) of enrterococci against vancomycin antibiotic was determined by standard broth dilution method, Mueller-Hinton broth, $\mathrm{pH}$ 7.2-7.4 was used as the test medium and inoculated with the turbidity adjusted suspension of isolate to achieve a final inoculums [ 10 ]. The National Committee for Clinical Laboratory Standard (NCCLS) guidelines were followed, which define enterococci for the MIC of vancomycin $\leq 16 \mu \mathrm{g} / \mathrm{ml}$ to be susceptible, while isolates for which the MIC is 16 to 64 $\mu \mathrm{g} / \mathrm{ml}$ are intermediate resistance and those for which the MIC is $\geq 128 \mu \mathrm{g} / \mathrm{ml}$ are resistant [ 11,12 ].

\section{Results:}

From 65 isolates of enterococci, 22 isolates (33.84\%) were appeared vancomycin resistant (resistant and intermediate; 12 isolates from clinical sources and 10 isolates from hospital environment).

Fourteen isolates $(21.53 \%)$ were vancomycin resistant enterococci, which $\mathrm{MIC}$ are $\geq 128$ $\mu \mathrm{g} / \mathrm{ml}$. On the other hand, $8(12.30 \%)$ isolates were showed an intermediate vancomycin resistant (VIRE) with MIC 16 to $64 \mu \mathrm{g} / \mathrm{ml}$. Other isolates $43(66.15 \%)$ were sensitive to vancomycin with $\mathrm{MIC} \leq 16 \mu \mathrm{g} / \mathrm{ml}$ (table 2 ).

In comparison for the data of MIC with disc diffusion method, the results showed that all of the 8 vancomycin intermediate isolates appear sensitivity to vancomycin by disc method. 


\section{J.Thi-Qar Sci.}

Table 1: The sources and frequencies of isolates

\begin{tabular}{|c|l|l|}
\hline I-Clinical samples & No. & $\%$ \\
\hline Stool & 12 & 18.46 \\
\hline Urine & 8 & 12.30 \\
\hline Vaginal swabs & 4 & 6.15 \\
\hline Intra-abdomimal \& pelvic wounds & 10 & 15.38 \\
\hline Blood culture & 2 & 3.07 \\
\hline 2-Hospital environment samples & & \\
\hline Operating theatres & 8 & 12.30 \\
\hline Bed wards & 4 & 6.15 \\
\hline Floor & 5 & 7.69 \\
\hline Medical instruments & 2 & 3.07 \\
\hline Total & 10 & 15.38 \\
\hline & 65 & 100 \\
\hline
\end{tabular}

Table 2: The MIC of vancomycin against enterococci from different samples

\begin{tabular}{|c|c|c|c|c|c|c|c|c|c|c|c|c|}
\hline \multirow{2}{*}{ susceptibility } & \multirow[t]{2}{*}{$\mathrm{St}^{*}$} & \multirow[t]{2}{*}{$\mathrm{Ur}$} & \multirow[t]{2}{*}{ IAW } & \multirow[t]{2}{*}{$\mathrm{VS}$} & \multirow[t]{2}{*}{$\mathrm{BC}$} & \multirow[t]{2}{*}{ OP } & \multirow[t]{2}{*}{$\mathrm{BW}$} & \multirow[t]{2}{*}{ Fl } & \multirow[t]{2}{*}{ MI } & \multirow[t]{2}{*}{ SW } & \multicolumn{2}{|c|}{ Total } \\
\hline & & & & & & & & & & & No & $\%$ \\
\hline $\begin{array}{l}\text { Resistance } \\
\mathrm{MIC} \geq 128 \mathrm{\mu g} / \mathrm{n}\end{array}$ & 3 & 2 & 2 & 1 & - & 2 & 1 & 1 & - & 2 & 14 & 21.53 \\
\hline $\begin{array}{l}\text { Intermediate } \\
\text { resistance } \\
\text { MICl6-64 } \mu \mathrm{g} / \mathrm{m}\end{array}$ & 2 & 1 & 1 & - & - & 1 & 1 & 1 & - & 1 & 8 & 12.30 \\
\hline $\begin{array}{l}\text { Sensitive } \\
\mathrm{MIC} \leq 16 \mu \mathrm{g} / \mathrm{ml}\end{array}$ & 7 & 5 & 7 & 3 & 2 & 5 & 2 & 3 & 2 & 7 & 43 & 66.15 \\
\hline Total & 12 & 8 & 10 & 4 & 2 & 8 & 4 & 5 & 2 & 10 & 65 & 100 \\
\hline
\end{tabular}

*St: Stool specimens; Ur: Urine; IAW: Intra-abdominal and pelvic wounds; VS: Vaginal swabs; BC:Bloodcultures;

OP: Operating theatres; BW: Bed wards;Fl:Floor; MI: Medical instruments; SW: Sewage; IMR: Intermediate resistance. 


\section{Discussion:}

During the last years a number of studies have reported the presence of VRE in the environment. Although, only limited information is available regarding the possible connection between human VRE infections and potential environmental and animal reservoirs [4, 13]. The epidemiology of VRE has not been completely elucidated; we know that certain patients are at increased risk for VRE colonization or infection. These include critically sick patients, those with severe underlying disease or immunosuppressant, patients in the oncology or transplant wards, those with intra-abdominal or cardiothoracic surgical procedures, patients with indwelling urinary or central venous catheters, and those with prolonged hospitalization or receiving broad-spectrum antimicrobial and vancomycin therapy [ 5,14 ].

Resistance to vancomycin (MIC $\geq 128 \mu \mathrm{g} / \mathrm{ml}$ ) was found in $14(21.53 \%)$ isolates, and 8 $(12.30 \%)$ isolates as intermediate vancomycin resistant enterococci, this in agreement with other studies $[4,15,16]$, which reported that VRE isolates herein described are showing the overuse of antimicrobials.

The study showed that six isolates of VRE were isolated from the hospital environment, while eight were isolated from the clinical samples. It was initially feared that enterococci would acquire the Van gene coding for vancomycin resistance from other species, this finding suggests that hospitals may be the sources of VRE and other factors may exert a selective pressure [4 ].

Since the VanA and VanB resistance genes are transferable, antibiotics resistance might be carried to other microorganisms like methicillin- resistant Staphylococcus aureus, as was reported by Tenover et al. [17], therefore, these strains could be very difficult to treat with the antimicrobial drugs currently available. Isolation of enterococci resistant to multiple antibiotics has become increasingly common in the hospital setting. Extreme precautions should be taken to avoid the spread of these strains. Education, permanent vigilance, and appropriate use of antibiotics are the foundations to minimize this problem $[18,19]$.

\section{References:}

1.Brooks ,G.F ;Bultel , J.S. \& Morse, S.A .(2004) "Jawez Melnick and Adelbergs medical microbiology" $.23^{\text {nd }}$ edn. Lange McGraw -Hill, N.Y. 818 pp.

2.Lior,L.; Litt, M.; Hockin, J.(1996) Vancomycin-resistant enterococci on a renal ward in an Ontario hospital. CCDR, 22:125-128.

3.Knudtson,L.M. and Hartman, P. A. (1992) Routine procedures for isolation and identification of enterococci and fecal streptococci. Appl. Environ. Microbiol., 58(9): 3027-3031.

4.Al Jarousha ,A.; Saed ,A.M. and Afifi,H.(2008). Prevalence of multidrug resistant enterococci in nasocomial infection in Gaza Strip. J. Al-Aqsa Unv.,12:15-24.

5.Littvik,A.M.; Lopez,T.N.; Gonzalez,S.E.; Fernandez,C.M. and Pavan,J.V. (2006).Colonization with vancomycin-resistant enterococci (VRE) in intensive care unit patients in Cordoba City, Argentina. Revista Argentina de Microbiologia., 38: 28-30.

6.Uttley, A.H.C.; George, R.C.; Naidoo, J. (1989). High-level vancomycin-resistant enterococci causing hospital infections. Epidemiol. Infect., 103:173-181.

7.Handwerger, S.; Perlman, DC; Altarac, D and McAuliffe V. (1992). Concomitant high-level vancomycin and penicillin resistance in clinical isolates of enterococci. Clin. Infect. Dis., 14:655661.

8.Facklam, R.R.and Sahm, D.F. (1995) Enterococcus. In : Murray, P.R.; Baron, E.J.; Pfaller, M.A. Eds. Manual of Clinical Microbiology. $6^{\text {th }}$ edition. ASM Press, Washington, DC. 308-314. 
9. Alonso-Echanove,J.; Robles, B. and Jarvis,R. (1992). Proficiency of clinical laboratories in Spain in detecting vancomycin-resistant Enterococcus spp. Appl. Environ. Microbiol., 58(9): 3027-3031.

10. Montecalvo, M.A.; Horowitz, H., Gedris, C.(1994).Outbreak of vancomycin- ampicillin, and aminoglycoside-resistant Enterococcus faecium bacteremia in an adult oncology unit. Antimicrob. Agents Chemother., 38:1363-1367.

11. National committee for clinical laboratory standards.(1999). Performance standards for antimicrobial susceptibility testing. NCCLS approved standard M100-S9. National Committee for Clinical Laboratory Standards, Wayne, PA.

12. National committee for clinical laboratory standards (NCCLS). (2000). Methods for dilution antimicrobial susceptibility tests for bacteria that grow aerobically; Approved Standard $-5^{\text {th }}$ edn. NCCLS document M7- A5.NCCLS: Wayne, Pennsylvania.

13. Bates, E.M; Jordens,J.Z. and Griffiths, D.T.(2004). Farm animals as a putative reservoir for vancomycin-resistant enterococcal infections in man. J. Antimicrob. Chemother., 34: 507-516.

14. Boyd, D.A.; Conly, J.; Dedier, H .(2000). Molecular characterization of the vanD gene cluster and a novel insertion element in a vancomycin-resistant Enterococus isolated in Canada. J. Clin. Microbiol .,38:2392-2394.

15. Qadri, S.M.H.; Postle, A.G.; Qari, M. and Quraishi, M.A.H. (1997). Vancomycin resistant enterococci (VRE) as intestinal flora from poultry in Riyadh. Annals Saudi Med., 17(5): 553557.

16. Leclercq, R.;Derlot, E.; Duval, J. and Courvalin, P.(1988). Plasmid mediated resistance to vancomycin and teicoplanin in Enterococcus faecium. N. Engl. J. Med., 319:157- 161.

17. Tenover,F.C.; Weigel,L.M.; Appelbaum,P.C.; McDougal,L.K.; Chaitram, J. and McAllister,S.(2004).Vancomycin-resistant Staphylococcus aureus isolated from a patient in Pennsylvania. Antimicrob. Agents Chemother., 48: 275-280.

18. Murray, B.E.(1990).The life and times of the Enterococcus. Clin. Microbiol. Rev.,3:46-65.

19. Facklam, R.R., Collins, M.D.(1989).Identification of Enterococcus species isolated from human infections by a conventional test scheme. J. Clin. Microbiol., 27:731-734.

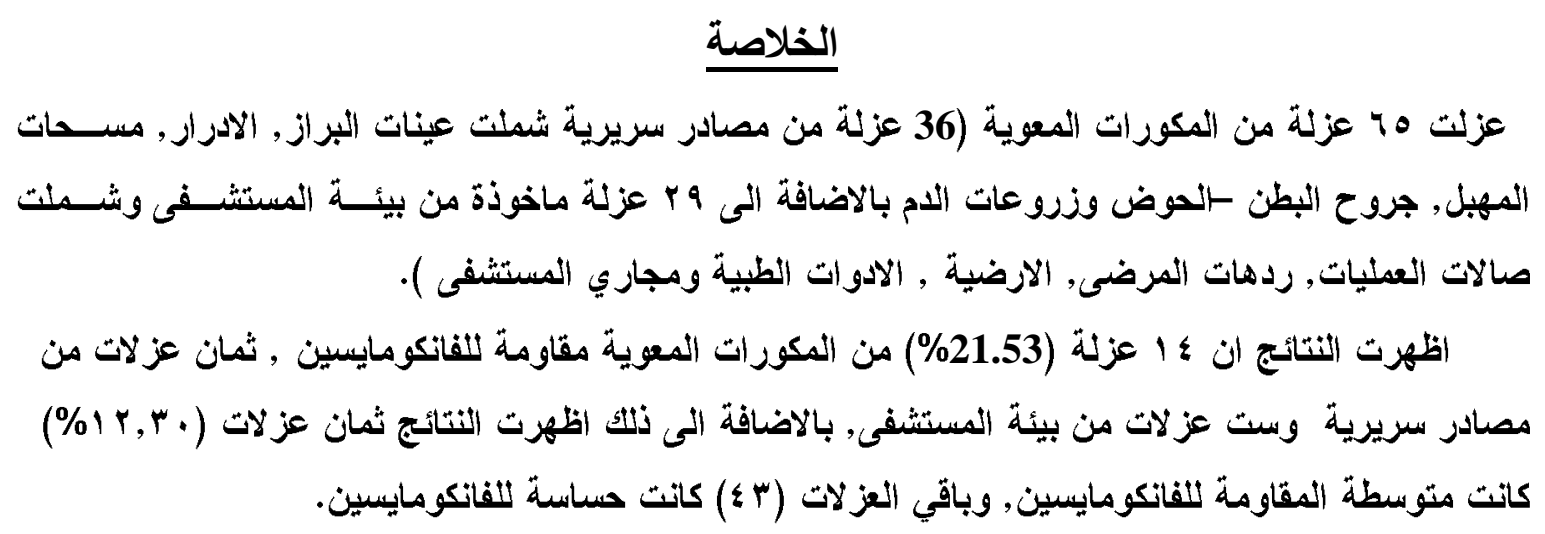

